\title{
JENIS - JENIS ODONATA DI KAWASAN STADION UTAMA RIAU, PEKANBARU
}

\author{
Novia Gesriantuti [1], Nofripa Herlina [1], Nurma Yunita [2] \\ [1]Dosen Program Studi Biologi Fakultas MIPA Dan Kesehatan UMRI, [2] \\ Mahasiswa Biologi Fakultas Mipa Dan Kesehatan UMRI \\ Fakultas MIPA dan Kesehatan \\ Universitas Muhammadilah Riau, Pekanbaru, Indonesia \\ Email:noviagesriantuti@umri.ac.id
}

\begin{abstract}
Abstrak
Penelitian dilakukan pada bulan April sampai Mei 2017 di Kawasan Stadion Utama Riau, Pekanbaru. Tujuan dari penelitian ini adalah untuk mengetahui jenis-jenis Odonata dan sebaran Odonata di Stadion Utama Riau. Penangkapan Odonata dilakukan dengan menggunakan metode jelajah (field by field method). Hasil penelitian ditemukan 15 Spesies yaitu Ictinogomphus decoratus, Pantala flavescens, Rhyothemis phyllis, Orthetrum sabina, Crocothemis servilia, Neurothemis fluctuans, Brachythemis contaminata, Diplacodes triviallis, Tholymis tillarga, Orthetrum testaceum, Trithemis aurora, Trithemis sp., Lestes concinnus, Ceriagrion auranticum dan Ceriagrion aeruginesum, semua spesies aktif pada pagi dan sore hari. Sebaran Odonata ditemukan lebih banyak pada Stasiun I dibandingkan Stasiun II dan Stasiun III.
\end{abstract}

Kata Kunci: Odonata, Identifikasi, Stadion Utama Riau

\begin{abstract}
The study was conducted from April to May 2017 at Riau Main Stadium, Pekanbaru. The purpose of this research is to know the diversity and distribution Odonata at Riau Main Stadium. Odonata capture is done using the field by field method. The results were found 15 species of Odonata i.e. Ictinogomphus decoratus, Pantala flavescens, Rhyothemis phyllis, Orthetrum sabina, Crocothemis servilia, Neurothemis fluctuans, Brachythemis contaminata, Diplacodes triviallis, Tholymis tillarga, Orthetrum testaceum, Trithemis aurora, Trithemis sp., Lestes concinnus, Ceriagrion auranticum and Ceriagrion aeruginesum. The highest distribution of Odonata is in Station I compared Station II and Station III.
\end{abstract}

Keyword: odonata,identification, Riau Main Stadium

\section{PENDAHULUAN}

Odonata merupakan kelompok serangga yang berukuran sedang sampai besar dan seringkali berwarna menarik. Serangga ini menggunakan sebagian besar hidupnya untuk terbang. Memiliki dua pasang sayap, berpembuluh darah yang tersusun seperti jala, antena pendek berbentuk rambut, alat mulut tipe pengunyah dan mata majemuk yang besar. Hidup di dua habitat yaitu pada saat pradewasa dalam air dan saat dewasa berada di dekat air. Sebagian besar spesies ditemukan di dekat air atau kolam, sungai, 
rawa-rawa dan di padang rumput, hutan, dan perbukitan (Borror, et al., 2005).

Odonata ditemukan mulai dari tepi pantai hingga ketinggian lebih dari 3.000 $m$ diatas permukaan laut (dpl). Pada beberapa jenis Odonata, memiliki kemampuan terbang yang baik dan memiliki daya jelajah wilayah yang luas, beberapa jenis lainnya merupakan penerbang yang lemah dan daya jelajah yang sempit. Faktor-faktor lingkungan seperti suhu, kelembaban udara, serta ketersediaan air dan makanan yang sesuai pada suatu habitat/ekosistem sangat diperlukan oleh Odonata untuk dapat menunjang kehidupannya (Rizal, et al., 2015).

Hampir 5.700 spesies Odonata dikenal di dunia saat ini. Beberapa spesies tersebar luas, sementara yang lain terbatas pada habitat yang sangat spesifik. Hingga saat ini belum bisa dipastikan berapa jumlah Odonata di Indonesia. Riset yang dilakukan oleh Indonesia Dragonfly Society (IDS) masih belum bisa memastikan berapa jumlah dari jenis Odonata di Indonesia, diperkirakan ada 700 jenis di Indonesia (Sigit, et al., 2013). Papua memiliki sekitar 400 spesies Odonata, Sumatera dan Kalimantan merupakan wilayah yang juga memiliki keragaman Odonata yang tinggi. Terdapat sekitar 280 spesies di masing-masing pulau yang banyak dijumpai di area lahan basah. Sulawesi dan Maluku, baru diketahui sekitar 140 spesies di masingmasing wilayah (Mongabay, 2016).

Pada ekosistem, Odonata berperan sebagai predator, dari berbagai serangga termasuk serangga hama. Odonata jarum (Subordo: Zygoptera) merupakan golongan Odonata yang bertubuh kecil berperan penting sebagai musuh alami dari populasi hama pada berbagai tanaman pangan (Borror, et al., 2005).

Peranan lain dari Odonata adalah sebagai bioindikator lingkungan yaitu indikator air. Odonata bertelur di dalam air kemudian menjadi nimfa (serangga yang hidup di dalam air). Nimfa Odonata sensitif terhadap pencemaran, sehingga membantu kita menandai kualitas air. (Mongabay, 2013).

Penelitian tentang keanekaragaman Odonata pada beberapa ekosistem telah pernah dilakukan antara lain oleh Ansori (2009), ditemukan 75 spesies disekitar persawahan Bandung Jawa Barat. Rohman (2012), ditemukan 18 spesies di Kawasan Kars Gunung Sewu Kecamatan Pracimantoro, Kabupaten Wonogiri, Jawa Tengah. Hanum, et al. (2013), 91 spesies ditemukan di Kawasan Taman Satwa Kandi Kota Sawahlunto Sumatera Barat. Herpina, et al. (2014), 5 spesies ditemukan di Komplek Perkantoran Pemerintah Daerah Kabupaten Rokan Hulu. Hermawan, et al. (2015), 22 spesies ditemukan di Taman Kota Bumi Serpong Damai, Tangerang Selatan, Banten. Siregar (2016), 31 spesies ditemukan di Kampus Hijau Universitas Sumatera Utara.

Stadion Utama Riau memiliki kolam, lapangan parkir (halaman Stadion Utama Riau) dan ruang terbuka umum. Di sekitar kolam ditumbuhi berbagai tumbuhan seperti ilalang (Imperata cylindrica L.), senduduk (Melastoma malabathricum L.) dan putri malu (Mimosa pudica L.). Kawasan ini cocok sebagai habitat bagi berbagai jenis Odonata. Hal ini dapat dilihat dengan banyaknya Odonata yang berterbangan di sekitar kolam (pengamatan langsung). Ruang terbuka umum juga dimanfaatkan oleh masyarakat untuk aktivitas seperti 
berjualan, tempat berolahraga ataupun tempat bermain terutama pada sore hari. Kondisi ini akan mempengaruhi penyebaran Odonata sehingga perlu dilakukan penelitian tentang keanekaragaman Odonata di Kawasan Stadion Utama Riau.

\section{METODOLOGI PENELITIAN}

Penelitian dilaksanakan pada bulan April sampai Mei 2017. Lokasi penelitian dilakukan di kawasan Stadion Utama Riau, Pekanbaru. Identifikasi Odonata dilakukan di Laboratorium Biologi, Fakultas MIPA dan Kesehatan, Universitas Muhammadiya Riau.

Alat yang digunakan dalam penelitian adalah jaring serangga (insect net), jarum serangga, kertas papilot, Thermometer, Hygrometer, gunting, kantong plastik, kertas label, botol killing, pinset, styrofoam, kotak koleksi serangga (insektarium), alat tulis dan kamera. Bahan yang digunakan adalah kapur barus, kapas, dan kloroform.

\section{Metode Penelitian}

Penelitian menggunakan metode observasi dengan cara tangkap langsung menggunakan jaring serangga (Insect Net). Pengoleksian dilakukan di daerah sekitar kolam, sekitar lapangan parkir dan ruang terbuka umum Stadion Utama Riau. Identifikasi dilakukan dengan mengamati ciri-ciri Odonata dari bagian kepala, toraks (dada), sayap dan abdomen (perut) dari masing-masing spesies Odonata yang ditemukan.

\section{Prosedur Kerja}

\section{Penentuan Stasiun Penelitian}

\begin{tabular}{lll}
\multicolumn{2}{c}{ Penentuan } & Stasiun penelitian \\
dilakukan dengan & metode purposive \\
sampling dengan & mempertimbangkan
\end{tabular}

kondisi lokasi penelitian. Pada penelitian ini di tetapkan 3 stasiun penelitian yaitu:

Stasiun I : sekitar kolam Kawasan Stadion Utama Riau.

Stasiun II : sekitar lapangan parkir Kawasan Stadion Utama Riau.

Stasiun III: ruang terbuka umum Kawasan Stadion Utama Riau.

\section{Penangkapan Odonata}

Penangkapan Odonata dilakukan dengan menggunakan metode jelajah (field by field method) dan pendataan jenis Odonata dilakukan dengan metode tangkap langsung Odonata yang dijumpai. Penangkapan Odonata dilakukan pada pagi hari yaitu pukul 08.00-11.00 WIB, siang hari pukul 14.00-18.00 WIB. Penangkapan Odonata dilakukan 2 kali dalam 1 minggu pada stasiun yang sama selama 1 bulan atau sampai tidak ada penambahan jumlah spesies lagi. Penangkapan pada masingmasing lokasi di lakukan pada hari yang berbeda. Penangkapan seluruh Odonata hanya dilakukan pada penangkapan pertama. Pada penangkapan selanjutnya Odonata yang ditangkap hanya spesies baru yang belum ditemukan pada penangkapan sebelumnya.

Sampel yang didapat dimasukkan ke dalam botol pembunuh yang telah diberi kloroform. Sampel yang telah mati ditusuk bagian ujung abdomen hingga toraks dengan menggunakan batang rumput agar Odonata tidak rusak, kemudian dimasukkan ke dalam kertas papilot dan diberi label. Pengukuran kelembaban udara dan suhu udara di lapangan dilakukan pada saat pengambilan sampel. 


\section{Pengawetan Odonata}

Sampel yang sudah diambil dikeluarkan dari kertas segitiga dan diawetkan dengan cara merentangkan sayap dan toraks ditusuk dengan menggunakan jarum serangga pada styrofoam. Kemudian dibiarkan kering setelah kering sampel disimpan dalam kotak spesimen, kemudian dijaga agar tetap kering dan diberi kapur barus untuk menghindari jamur dan semut.

\section{Identifikasi Odonata}

Identifikasi jenis Odonata dilakukan dengan memperhatikan warna, bentuk tubuh, bentuk dan posisi sayap (Sigit, et al., 2013). Identifikasi dilakukan dengan menggunakan buku "Study of Insects" (Borror, 2005), Naga Terbang Wendit (Sigit, 2013). Australian's Dragonflies (Watson et al., 1991) dan Common dragonflies in Sabah, Malaysia (Dragonflies of North Borneo, 2016).

\section{Analisis Data}

Odonata yang didapatkan dikelompokkan berdasarkan famili, genus dan spesies lalu difoto dan dibuat deskripsinya. Sebaran Odonata dapat dilihat berdasarkan keberadaan masingmasing Odonata pada masing-masing stasiun dan waktu penangkapan.

\section{HASIL DAN PEMBAHASAN}

Berdasarkan hasil penelitian, Odonata yang ditemukan terdiri dari 2 Subordo, 4 famili, 12 genus dan 15 spesies yaitu Ictinogomphus decoratus, Pantala flavescens, Rhyothemis phyllis, Orthetrum sabina, Crocothemiss servilia, Neurothemis fluctuans, Brachythemis contaminata, Diplacodes triviallis, Tholymis tillarga, Orthetrum testaceum, Trithemis aurora, Trithemis sp., Lestes concinnus, Ceriagrion auranticum dan Ceriagrion aeruginesum. Jenis-jenis Odonata yang ditemukan bervariasi, baik pada masing-masing stasiun maupun pada waktu penangkapan Hasil penelitian dapat dilihat pada Tabel 1.

Tabel 1. Sebaran keberadaan Odonata pada masing-masing stasiun dan waktu penangkapan di Kawasan Stadion Utama Riau, Pekanbaru.

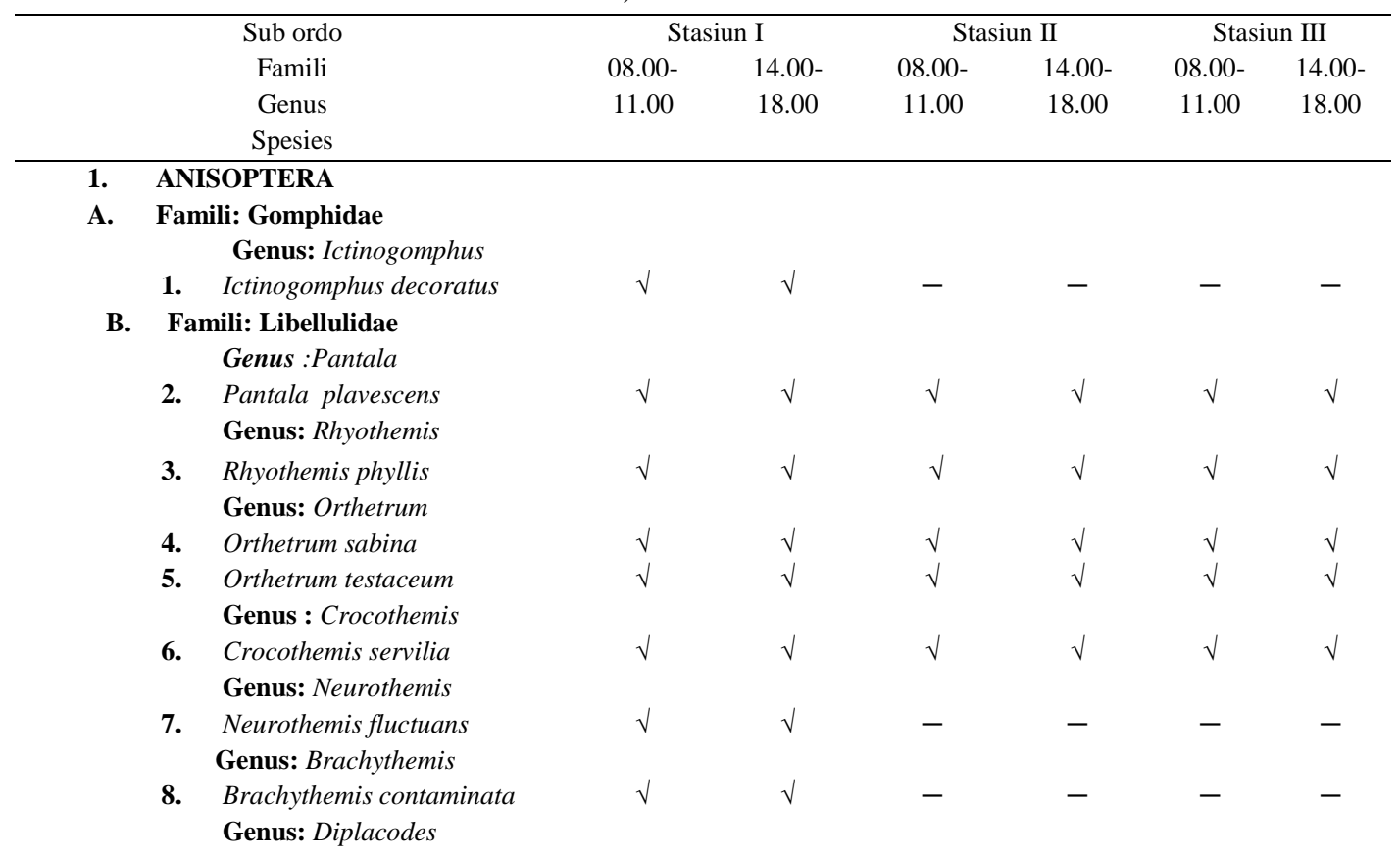




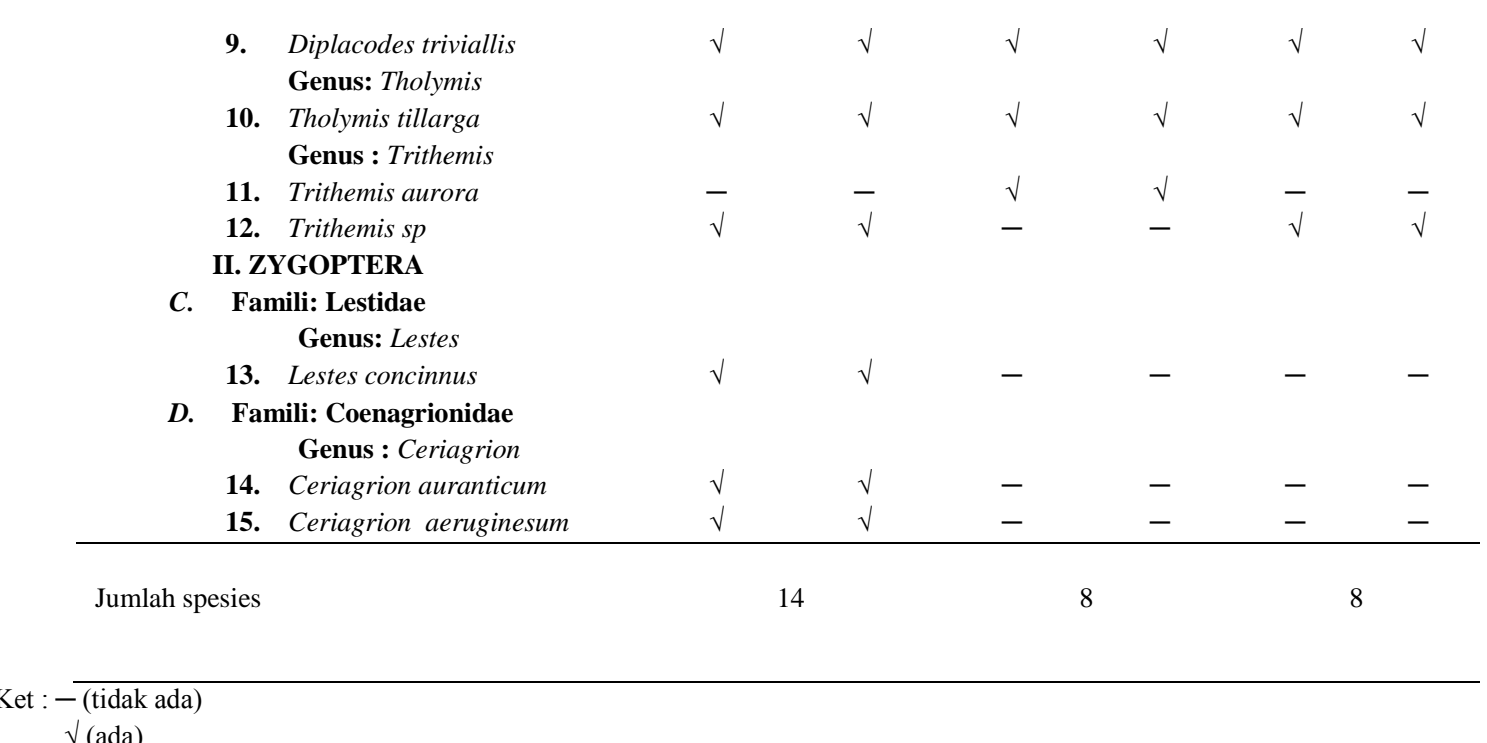

$\checkmark$ (ada)

Tabel 1 menunjukkan bahwa semua Odonata yang ditemukan aktif pada pagi dan sore hari. Sebaran Odonata yang paling tinggi yaitu pada Stasiun I dibandingkan Stasiun II dan Stasiun III. Hal ini diduga karena pada kawasan di Stasiun I terdapat kolam yang merupakan areal perairan yang cocok untuk berkembang biak Odonata, sehingga di Stasiun I lebih banyak ditemukan Odonata. Selain itu dipinggiran kolam banyak ditumbuhi tumbuhan seperti ilalang (Imperata cylindrica L.) dan senduduk (Melastoma malabathricum L.). Tumbuhan ini merupakan tempat hidup serangga yang menjadi sumber makanan bagi Odonata dan juga dijadikan sebagai tempat hinggap bagi Odonata. Sedangkan pada Stasiun II dan Stasiun III Odonata lebih sedikit ditemukan, hal ini disebabkan pada Stasiun II merupakan kawasan yang dijadikan tempat parkir, sedangkan stasiun III merupakan kawasan terbuka umum, dimana pada sore hari lebih ramai untuk aktivitas masyarakat seperti berjualan, areal bermain anak-anak dan tempat berolah raga, sehingga menyebabkan terganggunya aktivitas Odonata.

Pada Stasiun I ditemukan 6 spesies Odonata yang tidak ditemukan pada
Stasiun II dan Stasiun III yaitu dari Sub Ordo Anisoptera ditemukan 3 spesies yaitu Ictinogomphus decoratus, Neurothemis fluctuans, Brachythemis contaminata, sedangkan dari Sub Ordo Zygoptera ditemukan 3 spesies yaitu Lestes concinnus, Ceriagrion auranticum dan Ceriagrion aeruginesum, sedangkan pada Stasiun II terdapat 1 spesies Odonata yang berbeda dari Stasiun I dan Stasiun III yaitu Trithemis aurora.

Pada penelitian Hanum, et al. (2013), Subordo Zygoptera ditemukan disekitar genangan air, sekitar pacuan kuda dan pinggiran danau yang kebanyakan sedang hinggap pada tumbuhan seperti ilalang (Imperta cylindrica), Cyperacea dan Dipterocarpacea.

\section{PENUTUP}

\section{Kesimpulan}

Berdasarkan hasil penelitian dapat disimpulkan yaitu:

1. Odonata yang ditemukan terdiri dari 15 spesies yaitu Ictinogomphus decoratus, Pantala plavescens, Rhyothemis phyllis, Orthetrum sabina, Crocothemis servilia, Neurothemis fluctuans, Brachythemis contaminata, Diplacodes triviallis, Tholymis 
tillarga, Orthetrum testaceum,

Trithemis aurora, Trithemis sp., Lestes concinnus, Ceriagrion auranticum dan Ceriagrion aeruginesum, semuanya aktif pada pagi dan sore hari.

2. Sebaran Odonata yang paling banyak yaitu pada Stasiun I dibandingkan Stasiun II dan Stasiun III.

\section{DAFTAR PUSTAKA}

Ansori, 2009. Kelimpahan Dan Dinamika Populasi Odonata Berdasarkan Hubungannya Dengan Fenologi Padi Di Beberapa Persawahan Sekitar Bandung Jawa Barat, Jurnal Exacta 7(2): 69-75.

Borror, D. J., C. A. Triplehorn And N. F. Johnson. 2005. Pengenalan Serangga. Edisi VI. Terjemahan Soetiyono, S. Gadja Mada Press. Yogyakarta.

Hanum, S. O., Salma S., dan Dahelmi. 2013. Jenis-Jenis Capung (Odonata) Di Kawasan Taman Satwa Kandi Kota Sawahlunto, Sumatera Barat.

Herpina, R., Ade, Y.F., dan Afnianti, E., 2014. Jenis-Jenis Odonata (Odonata : Anisoptera) Di Komplek Perkantoran Pemerintah Daerah (PEMDA) Kabupaten Rokan Hulu.

Hermawan, S. A., dan Fitriana, N., 2015. Jenis Dan Fluktuasi Odonata Pada Taman Kota Bumi Serpong Damai, Tangerang Selatan, Banten. Pros Sem Nas Masy Biodiv Indon 1(8):1795-1801.

Mongabay, 2013. Odonata : Si Jagoan Mungil Penjaga Air Untuk Manusia.Yogyakarta.
Mongabay, 2016. Begini Dampak Perubahan Iklim Terhadap Penurunan Populasi Capung. Denpasar.

Rohman, A., 2012. Keanekaragaman Jenis Dan Distribusi Capung (Odonata) Dikawasan Kars Gunung Sewu Kecamatan Pracimantoro, Kabupaten Wonogiri, Jawa Tengah.

Rizal, S., dan Hadi, M., 2015. Inventarisasi Jenis Capung (Odonata) Pada Areal Persawahan Di Desa Pundenarum Kecamatan Karangawen Kabupaten Demak. Bioma 17(1):16-20.

Sigit, W., Feriwibisono, B., Nugrahani, P. M., Putri, B., dan Makitan, T. 2013. Naga Terbang Wendit. Keanekaragaman Capung Perairan Wendit, Malang Jawa Timur. Indonesia Dragonfly Society. Jawa Timur.

Siregar, A.Z., 2016. Keanekaragaman Dan Konservasi Status Capung Di Kampus Hijau Universitas Sumatera Utara, Medan-Indonesia. Jurnal Pertanian Tropik 3(1): 25-30.

Theischinger, G., 2009. Identification Guide To The Australian Odonata. Department Of Environment, Climate Change And Water NS. 